\title{
Phage Therapy in Bacterial Infections Treatment: One Hundred Years After the Discovery of Bacteriophages
}

\author{
Agata Anna Cisek ${ }^{1}$ Iwona Dąbrowska ${ }^{1}$ Karolina Paulina Gregorczyk ${ }^{2}$ • \\ Zbigniew Wyżewski ${ }^{2}$
}

Received: 18 April 2016/Accepted: 21 November 2016/Published online: 28 November 2016

(c) The Author(s) 2016. This article is published with open access at Springerlink.com

\begin{abstract}
The therapeutic use of bacteriophages has seen a renewal of interest blossom in the last few years. This reversion is due to increased difficulties in the treatment of antibiotic-resistant strains of bacteria. Bacterial resistance to antibiotics, a serious problem in contemporary medicine, does not implicate resistance to phage lysis mechanisms. Lytic bacteriophages are able to kill antibiotic-resistant bacteria at the end of the phage infection cycle. Thus, the development of phage therapy is potentially a way to improve the treatment of bacterial infections. However, there are antibacterial phage therapy difficulties specified by broadening the knowledge of the phage nature and influence on the host. It has been shown during experiments that both innate and adaptive immunity are involved in the clearance of phages from the body. Immunological reactions against phages are related to the route of administration and may vary depending on the type of bacterial viruses. For that reason, it is very important to test the immunological response of every single phage, particularly if intravenous therapy is being considered. The lack of these data in previous years was one of the reasons for phage therapy abandonment despite its century-long study. Promising results of recent research led us to look
\end{abstract}

Agata Anna Cisek

gutkac@op.pl

1 Division of Microbiology, Department of Preclinical Sciences, Faculty of Veterinary Medicine, Warsaw University of Life Sciences-SGGW, Ciszewskiego 8, 02-786 Warsaw, Poland

2 Division of Immunology, Department of Preclinical Sciences, Faculty of Veterinary Medicine, Warsaw University of Life Sciences-SGGW, Ciszewskiego 8, 02-786 Warsaw, Poland forward to a phage therapy that can be applied on a larger scale and subsequently put it into practice.

\section{History of Bacteriophage}

The history of phage therapy could be separated into four timespans, according to Summers et al. [48].

\section{Early Enthusiasm}

Bacteriophages were discovered by English microbiologist Twort in 1915 [1] but "the bacteriophage phenomenon" era began after publication in 1917 by a French-Canadian microbiologist Felix d'Herelle. During his investigations, he observed "invisible microbes" in filtrates of stool from patients suffering from dysentery that were "antagonistic" to bacteria. He surmised that this filterable virus, "ultraviruses," was a cofactor of bacterial infection. However, he proved that phage titers increased in disease progression and peaked during recovery. After those successes, d'Herelle branched out his investigations on humans. At first, he had tested the safety of phage suspension on himself, his co-workers, and family, then on patients suffering from "bacillary dysentery" and cholera (since 1919). After that, phages were applied as a therapy to wound recovery. Another experiment that focused on the healing value of phages investigated Salmonella gallinarum as an infectious agent of avian typhosis (published in 1926). This test also confirmed phage protection, as well as it did against other species, like Pasteurella multocida (bovine hemorrhagic septicaemia, published in the same year). Nevertheless, the first publication about phage therapy described the work of Bruynoghe and Maisin. Their results were published in 1921 [1, 48]. 


\section{Critical Scepticism}

Despite the fact that many early experiments of phage therapy reported positive results, there were also some disappointments. In 1934, a report was published in which previously released data were criticized. In the author's opinion, the biological viral nature of phage was not known well enough, both their strengths and limitations. Moreover, the report showed mistakes such as no standard in phage preparation and no criteria to compare the investigations' results [1].

\section{Abandonment}

War World II and the discovery of antibiotics reversed away the study in bacteriophage investigation, especially in the USA. The effortlessness of production, broad spectrum of activity, and stability in the preparation process were the advantages of antibiotics. In Europe, by contrast, two military-expanded countries (the Soviet Union and Germany) used phages as a medical treatment for healing wounds. In the Soviet Union, applications of phages were mainly driven by cost-effective and ideational motives ("preponderance" of Soviet science over the capitalist West) [47]. Moreover, The State Serum and Vaccine Institute in Tbilisi, Georgia, founded, among others, by d'Herelle was one of the major centres of phage therapy of that time [49]. A curious about phage therapy is the fact that the Pasteur Institute, the mother institution of d'Herelle where he worked on bacteriophages, obtained their bacterial viruses mainly from Russia or Georgia, even at the present time [1].

Another reason of abandoning the bacteriophage therapy in post-war time was the problem of phage-resistant bacteria, an unwittingness of pathogenic mechanisms in bacteria and of the nature of interactions between phage and their host. This lack of knowledge also included DNA restriction, an absence of models of animal diseases and listed lapses in experimental design [2].

\section{Recent Interest and Reappraisal}

In the 1970s, in Pakistan several experiments of the use of bacteriophages (prepared in the USSR), in the treatment of cholera were sponsored by WHO [27, 29]. A conclusion of these articles could be a statement that treatment of cholera with bacteriophage is not as effective as therapy with antibiotic (tetracycline); however, anti-cholera phage can selectively reduce the majority of vibrios without interfering with other intestinal microorganisms, and without any noticeable toxic effect on the patient. Therefore, bacteriophage might be a helpful study instrument.
Another set of articles about phage therapy applied as the treatment of diarrohea (models of mice and farm animals infected with Escherichia coli) concluded that bacteriophages could be employed both in treatment and prophylaxis [41-44]. These works were the beginning of western phage renaissance, which was propelled also by the rich trove of Soviet and Polish work. Research in Poland has been done mainly in connection with the Hirszfeld Institute of Immunology and Experimental Therapy in Wroclaw and has involved thousands of patients. Furthermore, those studies are deemed to be one of the most precisely documented [1]. In the whole history of bacteriophage therapy, there were a lot of investigations including also other etiological factors of diseases of both animals and humans such as Acinetobacter, Burkholderia, Citrobacter, Enterobacter, Enterococcus, Proteus, Pseudomonas, Shigella, Staphylococcus and Streptococcus $[47,48]$. The newest scientific research in the field of phage therapy was presented in the following sections of this article.

\section{How Do Bacteriophages Kill Bacteria?}

The increasing number of antibiotic-resistant bacterial strains is a serious problem in contemporary medicine. What is important is the fact that these bacteria do not implicate resistance to phage lysis mechanisms. Lytic bacteriophages are able to kill antibiotic-resistant bacteria at the end of the phage infection cycle. Most of them utilize two-component lysis systems to destroy a bacterial cell wall in order to release progeny virions. Thus, the development of phage therapy is a potential way to improve treatment of bacterial infections.

The course of a replication cycle is the criterion to divide bacteriophages into lytic and lysogenic ones. The release of lytic phage progeny from infected cells requires bacterial lysis. Scientific studies on phage lytic mechanisms contribute to the development of phage therapy. Some lytic bacteriophages use single proteins, amurins, to inhibit the synthesis of peptidoglycan [56]. However, most of them utilize two groups of proteins to kill the host cell. The first ones, holins, synergize with the second ones, endolysins, to cause lysis. Together, they make up the holin-lysin systems [10, 23].

Holins are involved in the host cell lysis triggering process. Their role is to perforate the host cytoplasmic membrane and thus to cooperate with endolysins by giving them an access to bacterial peptidoglycan. Therefore, holins determine the time of bacterial lysis. Acting at a precise time point, they control bacterial murein accessibility for phage endolysins and thus they synchronize the 
activity of the holin-lysin system with the late-phase events of the phage replication cycle [8, 39].

The primary structure of holins is not well conserved in evolution. However, differences in the amino acid sequences among holins are not reflected by their function. Every holin has at least one hydrophobic transmembrane domain (TMD) as well as C-terminal hydrophilic domain that carries a high electric charge. There are three classes of holins. Class I includes proteins that have more than 95 amino acid residues in length. These holins has three TMDs. Holins belonging to Class I are represented by Staphylococcus aureus bacteriophage p68 hol15 protein and Escherichia coli phage $\lambda \mathrm{S} 105$ protein. Holins belonging to class II have 65-95 amino acid residues in length and they have two TMDs. Lambdoid phage $21 \mathrm{~S}$ protein and Clostridium perfringens bacteriophage (3626 hol3626 protein are members of this class. Class III holins form only one TMD and are represented by the phage (DCP26F holin [8, 31, 38, 39, 50].

$\mathrm{S} 105$, the product of the phage $\lambda \mathrm{S}$ gene expression, is the most widely studied holin. S105 localizes the plasma membrane and, at a proper time point, it forms lethal lesions (holes) in lipid bilayer [8]. The average diameter of membrane holes is more than $340 \mathrm{~nm}$ [51].

Phage endolysins are enzymatic proteins responsible for cell wall degradation [54]. Bacteriophages use them to hydrolyze the peptidoglycan of the infected bacteria [37]. Endolysins perform activities of endopeptidase, amidase, glycosidase or lytic transglycosylase to kill bacterial cell by murein destruction $[9,22,30]$. Acting at the end of the phage replication cycle, endolysins promote the release of progeny virions. Endolysins directed against gram-negative bacteria have different structures from those targeting gram-positive ones, reflecting differences between enzyme targets. Gram-negative bacteria are surrounded by the outer membrane, and therefore the access to the cell wall is restricted from the outside. It seems to be the reason why endolysins targeting gram-negative bacteria are small globular proteins composed of only one domain, called enzymatically active domain (EAD) [37], whereas endolysins directed against gram-positive microorganisms have also cell wall binding domain (CBD) [4, 23, 24]. Enzyme targeting gram-positive bacteria binds to the cell wall through its CBD and thus remains immobilized on peptidoglycan surface. CBD contributes to the hydrolytic effects of endolysin by synergizing with EAD that performs an acatalytic function of enzymatic protein. During this process, endolysin remains tightly bound to one site of the peptidoglycan structure [37].

The holin-lysin system is responsible for termination of the phage infection cycle at a specific time point. The effect of endolysins on bacterial cell wall is subjected to precise timing through mechanism explained by the dual-start model. In this model, the time of bacterial lysis is dependent on the proportion between holin and its antagonist, antiholin. Both of them are encoded by an open reading frame. The ratio of holin to antiholin is strictly regulated by controlling their expression at the translational level. Elevation of the holin-antiholin ratio is followed by the loss of plasma membrane integrity [39], which allows endolysin to reach periplasm and begin to degrade the host peptidoglycan [51].

\section{Interactions Between Bacteriophages and Host Immune System During Phage Therapy}

Phage therapy may carry a risk of immunological reactions, that is why studies about interactions between phages and immunity are very important for the rational use of this treatment. Immune response against bacteriophages depends on the localization of bacterial infection and the injection site of therapeutic phages. Under physiological conditions, some phages are associated with the eukaryotic component of a gut microbiota and ingested food [35]. High frequency of natural contact of animals/humans with various types of phages is evidenced by the anti-phage antibodies detected in the sera of different species (e.g. human) [44]. Furthermore, an oral administration of phages during phage therapy of bacterial infection caused by Staphylococcus, Klebsiella, Escherichia, Proteus and Pseudomonas induces the production of antibodies as well [7]. There is no evidence of immunological complications after the consumption of large amounts of phages [36]. Moreover, the topical applications of phages have not shown any side effects [57]. A different situation is observed in the other internal organs and blood stream, which are not natural environment for phages. Intravenous administration of bacterial pathogens strongly stimulates both innate and adaptive immunity [28]. Furthermore, studies show that phages can penetrate into the circulation, regardless of the route of administration [7]. If there are no host bacteria for specific phages, they are rapidly removed from the blood and internal organs by phagocytic cells [28]. Moreover, bacterial predators are internalized and eliminated by cells of the reticuloendothelial system of liver and spleen. Interestingly, Kupffer cells (specialized macrophages which are located in the liver) can phagocyte phages four times faster than spleen macrophages, which suggests that arrested bacterial pathogens in spleen may stimulate lymphocytes to produce antibodies [7, 14]. Innate immunity, known as the first line of defence, is often sufficient to eliminate pathogens before the activation of adaptive immune response. Studies have shown that patients subjected to phage therapy were characterized by the decreasing number of mature neutrophils and the 
increasing number of neutrophil precursors in the peripheral blood [55]. These results indicated that phage preparations can activate innate immune response, which is helpful in the clearance of bacterial infection. On the other hand, phages can affect immune cells' metabolic activities as well. For instance, studies have shown that bacteriophages markedly inhibit ROS production in response to pathogenic bacteria and suggest that phages decrease antibacterial innate immunity [32]. However, the relevance of these findings in relation to clinical situations is discussed.

During phage therapy, phages are able to induce specific antibodies (neutralizing antibodies) against them, which usually inhibit phage effectiveness to lyse the targeted bacteria in vivo $[15,16,25,46]$. In fact, neutralizing antibodies are defined as antibodies that bind epitopes within those parts of the virion essential for infecting the host cells [13]. However, it is not clear how long this type of antibodies will remain in circulation. Concentration of neutralizing antibodies depends on many aspects, for instance, (a) the route of phages administration (topical and oral administration cause a small increase of antibodies) and (b) the dosage protocol [47]. Studies have shown that anti-phage neutralizing antibodies are probably one of the most important factors responsible for the efficacy limitation of phage therapy [44]. However, Sulakvelidze et al. [46] suggested that the development of neutralizing antibodies should not be a significant problem during the initial treatment of acute infections, because the kinetics of phage action are much faster than the host's production of neutralizing antibodies. Nevertheless, anti-phage antibodies can be an obstacle if they are still present at the time the second course of treatment is administered. There are three ways to solve that problem. It might be envisaged to (a) repeat phage administration, (b) increase the phage concentration or (c) use different phages because resistance is different from one phage to another [46]. Despite the fact that anti-phage neutralizing antibodies occur during phage therapy, there is also an increasing level of non-neutralizing antibodies, IgM and later IgG, and enhancement of immune response after subsequent injections of some types of phages $[3,5]$.

Apart from the humoral immune response, cellular immunity also plays an important role against phages. Langbeheim has shown that subcutaneous injection of MS2 phages resulted in a strong hypersensitivity reaction in guinea pigs. Similar results have been obtained in vitro [21]. However, some other studies indicated that cellular immune responses play only a slight role in phage inactivation. They showed that the clearance of $\mathrm{T} 7$ phage in $\mathrm{T}$ cell-deficient mice was similar to that observed in the wildtype mice [45]. In view of the contradictory results, this issue requires further study. Interestingly, some studies have shown that phages can exert immunosuppressive activity. Over the study upon the role of bacteriophages in the development of transplantation tolerance, Górski observed that phages can inhibit the activation of $\mathrm{T}$ cells [17]. Moreover, Kniotek indicated that after phage administration the humoral immunity is decreased as well [20].

Altogether results suggest that it is very important to test the immunological response of every single phage, particularly if intravenous therapy is being considered. However, previous clinical and animal trials have not resulted in serious immunologic reactions during phage therapy [28].

\section{Phage Therapy Now}

Bacteriophages have been studied and used to control bacterial infections of patients in Poland, Georgia and Russia for nearly a century. Recently, more countries, including France, Belgium, Switzerland (Phagoburn project) and the USA, decided to join [33]. Phage Therapy Center of the Hirszfeld Institute of Immunology and Experimental Therapy in Wroclaw offers its patients experimental therapies against several bacterial diseases, including those caused by Acinetobacter, Burkholderia, Citrobacter, Enterobacter, Enterococcus, Escherichia, Klebsiella, Morganella, Proteus, Pseudomonas, Shigella, Salmonella, Serratia, Staphylococcus and Stenotrophomonas. Based on the data published by the Centre, $35-50 \%$ of patients treated there got positive therapy results. So far, the Centre does not offer treatment for infections caused by Streptococcus spp., Mycobacterium tuberculosis, Propionibacterium acnes, Borrelia spp., Helicobacter pylori, and Haemophilus influenza, nor Chlamydia spp. [19]. As for Eliava Phage Therapy Center in Tbilisi, phages are used there for the treatment of infections caused by Enterococcus faecalis of different serovars, E. coli (O11, O18, O20, O25, O26, O44, O55, O113, O125, O128), Proteus vulgaris, P. mirabilis, Pseudomonas aeruginosa, Salmonella (Paratyphi A, Paratyphi B, Typhimurium, Enteritidis, Heidelberg, Newport, Cholerae Suis, Oranienburg, Dublin, Anatum), Shigella flexneri (serovars 1, 2, 3, 4), Sh. sonnei (serovar 6), Sh. newcastle, Staphylococcus aureus, S. epidermidis, S. saprophyticus, and Streptococcus pyogenes, $S$. sanguis, $S$. salivarius and more [12]. In order to increase the antimicrobial activity and to decrease the risk of the phage resistance development, each treatment is a cocktail that contains at least a few bacteriophage strains. Therapy may be executed with the use of lytic or lysogenic phages. In case of the former, even though it is a method of choice, there is still a concern that phage therapy may worsen the health condition of patients since viral lytic cycle is followed by a release of 
bacterial endotoxins. In contrast, the use of temperate (lysogenic) phages leaves the possibility of transfer of virulence genes into so far non-virulent microbionts of patients. An extensive review over recent bacteriophage experimental trials has been described elsewhere [53].

Evaluation of phage potential in the treatment of human infections is an ongoing process. In the year 2016 alone, a few interesting papers of in vivo experiments on bacteriophages have been published. In the first one, a hypervariable region of a cell wall protein named PIPEF (phage infection protein from Enterococcus faecalis) was identified as a crucial factor of phage tropism for E. faecalis strains [11]. In vivo testing of phage predation on a gnotobiotic mouse model showed that through mutations in this hypervariable region of PIPEF E. faecalis acquired phage resistance.

Simultaneously to the mechanisms of acquired phage resistance in bacteria, possible ways of phage delivery to specific destinations are being studied. In Singla et al. [40], different approaches of incorporation of Klebsiella pneumoniae phage particles into liposomes as well as biodistribution of liposome-entrapped phages in various organs of BALB/c mice were evaluated. It turned out that liposome-entrapped phages were a few times more stable in blood and organs than free phages. These results allowed to assume that because of longer bioretentivity rates of those phages in lungs and kidneys, it makes them a suitable candidate for the treatment of $K$. pneumoniae-associated respiratory tract and urinary tract infections.

Interestingly, phage therapy may be used in a far different manner. Prophylactic use of bacteriophages resembles that described for bacterial probiotics. In essence, phages administered orally can eliminate diarrheic pathogens like Salmonella spp., Clostridium difficile and E. coli. They can also-if designed to do so-modulate the gastrointestinal microbiota composition in a preferred way, bringing further benefits for the host [1].

Also, phages were used to control the spread of Campylobacter jejuni and C. coli infections in chickens [6]. Although $C$. jejuni does not significantly influence the wellbeing of chickens, it is a human pathogen that does not only induce the food poisoning, but is also responsible for its long-term consequences, i.e. development of GuillainBarre syndrome, reactive arthritis and post-infectious irritable bowel syndrome [52]. Therefore, decreasing the load of $C$. jejuni in poultry products decreases the risk of people getting sick, and in that sense phage therapy may also be considered to have an indirect "probiotic" activity. On a note side, research on the use of phages in other applications, such as construction of antivenoms (phage display), and biocontrol in food manufacturing is still ongoing, yet looks very promising $[18,26,34]$.
Open Access This article is distributed under the terms of the Creative Commons Attribution 4.0 International License (http://crea tivecommons.org/licenses/by/4.0/), which permits unrestricted use, distribution, and reproduction in any medium, provided you give appropriate credit to the original author(s) and the source, provide a link to the Creative Commons license, and indicate if changes were made.

\section{References}

1. Abedon ST, Kuhl SJ, Blasdel BG, Kutter EM (2011) Phage treatment of human infections. Bacteriophage 1(2):66-85. doi:10. 4161/bact.1.2.15845

2. Barrow P, Lovell M, Berchieri A (1998) Use for control of experimental Escherichia coli septicemia and meningitis in of lytic bacteriophage chickens and calves. Clin Diagn Lab Immunol 5(3):294-298

3. Biswas B, Adhya S, Washart P, Paul B, Trostel AN, Powell B, Carlton R, Merril CR (2002) Bacteriophage therapy rescues mice bacteremic from a clinical isolate of vancomycin-resistant Enterococcus faecium. Infect Immun 70:204-210. doi:10.1128/IAI. 70.1.204-210.2002

4. Borysowski J, Weber-Dabrowska B, Gorski A (2006) Bacteriophage endolysins as a novel class of antibacterial agents. Exp Biol Med 231:366-377. doi:10.1016/j.tifs.2012.06.016

5. Capparelli R, Nocerino N, Iannaccone M, Ercolini D, Parlato M, Chiara M, Iannelli D (2010) Bacteriophage therapy of Salmonella enterica: a fresh appraisal of bacteriophage therapy. J Infect Dis 201(1):52-61. doi:10.1086/648478

6. Carvalho CM, Gannon BW, Halfhide DE, Santos SB, Hayes CM, Roe JM, Azeredo J (2010) The in vivo efficacy of two administration routes of a phage cocktail to reduce numbers of Campylobacter coli and Campylobacter jejuni in chickens. BMC Microbiol 10:232. doi:10.1186/1471-2180-10-232

7. Dạbrowska K, Świtała-Jeleń K, Opolski A, Weber-Dąbrowska B, Górski A (2005) Bacteriophage penetration in vertebrates. J Appl Microbiol 98:7-13. doi:10.1111/j.1365-2672.2004.02422.x

8. Dewey JS, Savva CG, White RL, Vitha S, Holzenburg A, Young R (2010) Micron-scale holes terminate the phage infection cycle. Proc Natl Acad Sci USA 107:2219-2223. doi:10.1111/mmi. 12439

9. Donovan DM, Foster-Frey J (2008) Lambda Sa2 prophage endolysin requires $\mathrm{Cpl}$-7-binding domains and amidase-5 domain for antimicrobial lysis of streptococci. FEMS Microbiol Lett 287:22-33. doi:10.1111/j.1574-6968.2008.01287.x

10. Drulis-Kawa Z, Majkowska-Skrobek G, Maciejewska B (2015) Bacteriophages and phage-derived proteins-application approaches. Curr Med Chem 22:1757-1773. doi:10.2174/ 0929867322666150209152851

11. Duerkop BA, Huo W, Bhardwaj P, Palmer KL, Hooper LV (2016) Molecular basis for lytic bacteriophage resistance in enterococci. MBio 7(4):e01304-e01316. doi:10.1128/mBio. 01304-16

12. Eliava Phage Therapy Center (2009) Phage applications. http:// www.mrsaphages.com/phage-applications. Accessed 9 June 2015

13. Forthal DN, Moog C (2009) Fc receptor-mediated antiviral antibodies. Curr Opin HIV AIDS 4(5):388-393. doi:10.1097/ COH.0b013e32832f0a89

14. Geier MR, Trigg ME, Merril CR (1973) Fate of bacteriophage lambda in non-immune germfree mice. Nature 246:221-223. doi:10.1038/246221a0

15. Geller BL, Kraus J, Schell MD, Hornsby MJ, Neal JJ, Ruch FE (1998) High titer, phage-neutralizing antibodies in bovine colostrum that prevent lytic infection of Lactococcus lactis in 
fermentations of phage-contaminated milk. J Dairy Sci 81:895-900. doi:10.3168/jds.S0022-0302(98)75648-6

16. Górski A, Międzybrodzki R, Borysowski J, Dąbrowska K, Wierzbicki P, Ohams M, Korczak-Kowalska G, Olszowska-Zaremba N, Łusiak-Szelachowska M, Kłak M, Jończyk E, Kaniuga E, Gołaś A, Purchla S, Weber-Dąbrowska B, Letkiewicz S, Fortuna W, Szufnarowski K, Pawełczyk Z, Rogóż P, Kłosowska D (2012) Phage as a modulator of immune responses: practical implications for phage therapy. Adv Virus Res 83:41-71. doi:10. 1016/B978-0-12-394438-2.00002-5

17. Górski A, Ważna E, Weber-Dąbrowska B, Dąbrowska K, Świtała-Jeleń K, Międzybrodzki R (2006) Bacteriophage translocation. FEMS Immunol Med Microbiol 46:313-319. doi:10.1111/j.1574-695X.2006.00044.X

18. Heyse S, Hanna LF, Woolston J, Sulakvelidze A, Charbonneau D (2015) Bacteriophage cocktail for biocontrol of Salmonella in dried pet food. J Food Prot 78:97-103. doi:10.4315/0362-028X. JFP-14-041

19. Instytut Immunologii i Terapii Doświadczalnej PAN (2015) Najczęstsze pytania. www.iitd.pan.wroc.pl/pl/OTF/Pytania.html. Accessed 10 June 2015

20. Kniotek M, Weber-Dąbrowska B, Dąbrowska K, Świtała-Jeleń K, Boratyński J, Wiszniowski M, Glinkowski W, Babiak I, Górecki A, Nowaczyk M, Górski A (2004) Phages as immunomodulators of antibody production. In: Monduzzi editore, genomic issues, immune system activation and allergy (immunology 2004). Medimond international proceedings Montreal, Canada, pp 33-37

21. Langbeheim H, Teitelbaum D, Arnon R (1978) Cellular immune response toward MS-2 phage and a synthetic fragment of its coat protein. Cell Immunol 38:193-197. doi:10.1016/00088749(78)90046-1

22. Linden SB, Zhang H, Heselpoth RD, Shen Y, Schmelcher M, Eichenseher F, Nelson DC (2015) Biochemical and biophysical characterization of PlyGRCS, a bacteriophage endolysin active against methicillin-resistant Staphylococcus aureus. Appl Microbiol Biotechnol 99:741-752. doi:10.1007/s00253-0145930-1

23. Loessner MJ (2005) Bacteriphage endolysins-current state of research and applications. Curr Opin Microbiol 8:480-487. doi:10.1016/j.mib.2005.06.002

24. Lopez R, Garcia E (2004) Recent trends on the molecular biology of pneumococcal capsules, tylic enzymes, and bacteriophage. FEMS Microbiol Rev 28:553-580. doi:10.1016/j.femsre.2004.05. 002

25. Ly-Chatain MH (2014) The factors affecting effectiveness of treatment in phages therapy. Front Microbiol 18(5):51. doi:10. 3389/fmicb.2014.00051

26. Magnone JP, Marek PJ, Sulakvelidze A, Senecal AG (2013) Additive approach for inactivation of Escherichia coli 0157:h7, Salmonella, and Shigella spp. on contaminated fresh fruits and vegetables using bacteriophage cocktail and produce wash. J Food Prot 76:1336-1341. doi:10.4315/0362-028X.JFP-12-517

27. Marcuk LM, Nikiforov VN, Scerbak JF, Levitov TA, Kotljarova RI, Naumsina MS, Davydov SU, Monsur KA, Rahman MA, Latif MA, Northrup RS, Cash RA, Hug I, Dey CR, Phillips RA (1971) Clinical studies of the use of bacteriophage in the treatment of cholera. Bull World Health Organ 45(1):77-83

28. Merril CR, Scholl D, Adhya S (2006) Phage therapy. In: Calendar R (ed) The bacteriophages. Oxford University Press, New York, pp 725-741

29. Monsur KA, Rahman MA, Huq F, Islam MN, Northrup RS, Hirschhorn N (1970) Effect of massive doses of bacteriophage on excretion of vibrios, duration of diarrhoea and output of stools in acute cases of cholera. Bull World Health Organ 42(5):723-732
30. Nelson DC, Schmelcher M, Rodriguez-Rubio L, Klumpp J, Pritchard DG, Dong S, Donovan DM (2012) Endolysins as antimicriobials. Adv Virus Res 83:299-365. doi:10.1016/B978-012-394438-2.00007-4

31. Pang T, Savva CG, Fleming KG, Struck DK, Young R (2009) Structure of the lethal phage pinhole. Proc Natl Acad Sci USA 106:18966-18971. doi:10.1073/pnas.0907941106

32. Przerwa A, Zimecki M, Switała-Jeleń K, Dabrowska K, Krawczyk E, Łuczak M, Weber-Dabrowska B, Syper D, Miedzybrodzki R, Górski A (2006) Effects of bacteriophages on free radical production and phagocytic functions. Med Microbiol Immunol 195(3):143-150. doi:10.1007/s00430-006-0011-4

33. Reardon S (2014) Phage therapy gets revitalized. Nature 510:15-16. doi:10.1038/510015a

34. Roncolato EC, Campos LB, Pessenda G, Costa e Silva L, Furtado GP, Barbosa JE (2015) Phage display as a novel promising antivenom therapy: a review. Toxicon 93:79-84. doi:10.1016/j. toxicon.2014.11.001

35. Reyes A, Semenkovich NP, Whiteson K, Rohwer F, Gordon JI (2012) Going viral: next-generation sequencing applied to phage populations in the human gut. Nat Rev Microbiol 10:607-617. doi:10.1038/nrmicro2853

36. Sarker SA, McCallin S, Barretto C, Berger B, Pittet AC, Sultana S, Krause L, Huq S, Bibiloni R, Bruttin A, Reuteler G, Brüssow H (2012) Oral T4-like phage cocktail application to healthy adult volunteers from Bangladesh. Virology 434:222-232. doi:10. 1016/j.virol.2012.09.002

37. Schmelcher M, Donovan DM, Loessner MJ (2012) Bacteriphage endolysins as novel antimicrobials. Future Microbiol 7:1147-1171. doi:10.2217/fmb.12.97

38. Seal BS, Fouts DE, Simmons M, Garrish JK, Kuntz RL, Woolsey R, Schegg KM, Kropinski AM, Ackermann HW, Siragusa GR (2011) Clostridium perfringen bacteriophages PhiCP39O and PhiCP26F: genomic organization and proteomic analysis of the virions. Arch Virol 156:25-35. doi:10.1007/s00705-010-0812-z

39. Shi Y, Yan Y, Ji W, Du B, Meng X, Wang H, Sun J (2012) Characterization and determination of holin protein of Streptococcus suis bacteriophage SMP in heterologous host. Virol J 9:70. doi:10.1186/1743-422X-9-70

40. Singla S, Harjai K, Raza K, Wadhwa S, Katare OP, Chhibber S (2016) Phospholipid vesicles encapsulated bacteriophage: a novel approach to enhance phage biodistribution. J Virol Methods 236:68-76. doi:10.1016/j.jviromet.2016.07.002

41. Smith HW, Huggins MB (1982) Successful treatment of experimental Escherichia coli infections in mice using phage: its general superiority over antibiotics. J Gen Microbiol 128(2):307-318. doi:10.1099/00221287-128-2-307

42. Smith HW, Huggins MB (1983) Effectiveness of phages in treating experimental Escherichia coli diarrhoea in calves, piglets and lambs. J Gen Microbiol 129(8):2659-2675. doi:10.1099/ 00221287-129-8-2659

43. Smith HW, Huggins MB, Shaw KM (1987) The control of experimental Escherichia coli diarrhoea in calves by means of bacteriophages. J Gen Microbiol 133(5):1111-1126. doi:10.1099/ 00221287-133-5-1111

44. Smith HW, Huggins MB, Shaw KM (1987) Factors influencing the survival and multiplication of bacteriophages in calves and in their environment. J Gen Microbiol 133(5):1127-1135. doi:10. 1099/00221287-133-5-1127

45. Srivastava AS, Kaido T, Carrier E (2004) Immunological factors that affect the in vivo fate of $\mathrm{T} 7$ phage in the mouse. J Virol Methods 115(1):99-104. doi:10.1016/j.jviromet.2003.09.009

46. Sulakvelidze A, Alavidze Z, Morris JG Jr (2001) Bacteriophage therapy. Antimicrob Agents Chemother 45:649-659. doi:10. 1128/AAC.45.3.649-659.2001 
47. Sulakvelidze A, Kutter E (2005) Bacteriophage therapy in humans. In: Sulakvelidze A, Kutter E (eds) Bacteriophages: biology and application. CRC Press, Boca Raton, pp 381-436

48. Summers WC (2001) Bacteriophage therapy. Annu Rev Microbiol 55:437-451. doi:10.1146/annurev.micro.55.1.437

49. Summers WC (2012) The strange history of phage therapy. Bacteriophage 2(2):130-133. doi:10.4161/bact.20757

50. Takáč M, Witte A, Bläsi U (2005) Functional analysis of the lysis genes of Staphylococcus aureus phage P68 in Escherichia coli. Microbiology 151:2331-2342. doi:10.1099/mic.0.27937-0

51. To KH, Young R (2014) Probing the structure of the S105 hole. J Bacteriol 196:3683-3689. doi:10.1128/JB.01673-14

52. Umaraw P, Prajapati A, Verma AK, Pathak V, Singh VP (2015) Control of Campylobacter in poultry industry from farm to poultry processing unit-a review. Crit Rev Food Sci Nutr. doi:10.1080/10408398.2014.935847

53. Viertel TM, Ritter K, Horz H-P (2014) Viruses versus bacterianovel approaches to phage therapy as a tool against multidrug- resistant pathogens. J Antimicrob Chemother 69:2326-2336. doi:10.1093/jac/dku173

54. Wang IN, Smith DL, Young R (2000) Holins: the protein clocks of bacteriophage infections. Annu Rev Microbiol 54:799-825. doi:10.1146/annurev.micro.54.1.799

55. Weber-Dabrowska B, Zimecki M, Mulczyk M, Górski A (2002) Effect of phage therapy on the turnover and function of peripheral neutrophils. FEMS Immunol Med Microbiol 34:135-138

56. Woźnica WM, Bigos J, Łobocka MB (2015) Lysis of bacterial cells in the process of bacteriophage release-canonical and newly discovered mechanisms. Postepy Hig Med Dosw 69:114-126

57. Wright A, Hawkins CH, Anggard EE, Harper DR (2009) A controlled clinical trial of a therapeutic bacteriophage preparation in chronic otitis due to antibiotic-resistant Pseudomonas aeruginosa; a preliminary report of efficacy. Clin Otolaryngol 34:349-357. doi:10.1111/j.1749-4486.2009.01973.x 